\title{
New Reduction Factor for Cracked Square Hollow Section K-joints
}

\author{
S.P. Vipin*1, A. Kolios ${ }^{1}$, S.T. Lie ${ }^{2}$ and L. Wang ${ }^{3}$ \\ ${ }^{I}$ Cranfield University, Offshore Energy Engineering Centre, Cranfield, MK43 OAL, United Kingdom \\ ${ }^{2}$ Nanyang Technological University, School of Civil and Environmental Engineering, 639798, Singapore \\ ${ }^{3}$ Coventry University, School of Mechanical, Aerospace and Automotive Engineering, CVI 5FB, United Kingdom \\ *E-mail: Vipin.Sukumara-Pillai@cranfield.ac.uk, Tel.: +44-1234754855
}

\begin{abstract}
Cracks are commonly observed at the hot spot stress location of tubular joints and it can be due to fatigue, accidental damage or corrosion. As a consequence, the plastic collapse load $\left(P_{\mathrm{c}}\right)$ of the tubular joints is reduced, and hence it is necessary to produce design guidance which can safely be used to estimate the static residual strength of cracked tubular structures in practice. This paper proposes a new expression for determining the reduction factor $\left(F_{\mathrm{AR}}\right)$ of cracked square hollow section (SHS) K-joints. A completely new and robust finite element mesh generator which is validated using the full scale experimental test results is used for the parametric study to propose the new $F_{\mathrm{AR}}$ expressions for cracked SHS K-joints. The crack area and the brace to chord width ratio $(\beta)$ are shown to have the most profound effect on the $P_{\mathrm{c}}$ load of cracked SHS K-joints. For a given value of crack area, the variation of the $F_{\mathrm{AR}}$ values is up to $3.6 \%$ for different values of $\beta$. Furthermore, the $F_{\mathrm{AR}}$ values calculated using the existing equation given in the latest BS 7910:2013+A1:2015 for circular hollow section (CHS) joints are revealed to be conservative up to $23.5 \%$.
\end{abstract}

Keywords: Cracks; Finite element analysis; Square hollow section K-joint; Plastic collapse load; Reduction factor

\section{Nomenclature}

a crack depth

Ac crack area 


$\begin{array}{ll}b_{0} & \text { chord width } \\ b_{1}, b_{2} & \text { brace width } \\ g & \text { gap distance } \\ h_{0} & \text { chord height } \\ h_{1}, h_{2} & \text { brace height } \\ l_{\mathrm{c}} & \text { chord length } \\ l_{\mathrm{w}} & \text { weld length } \\ P_{\mathrm{a}} & \text { total applied load } \\ P_{\mathrm{c}} & \text { plastic collapse load } \\ Q_{\beta} & \text { geometrical modifier } \\ t_{0} & \text { chord thickness } \\ t_{1, t 2} & \text { brace thickness } \\ \alpha & \text { chord length to half chord width ratio } \\ \beta & \text { brace to chord width ratio } \\ \gamma & \text { chord half width to thickness } \\ \tau & \text { ratio } \\ \theta 1, \theta_{2} & \text { brace thickness to chord thickness ratio } \\ & \text { brace to chord angle }\end{array}$

\section{Scope of the research}

The tubular joints such as circular hollow section (CHS) and square hollow section (SHS) joints are subjected to various types of loading throughout their lifespan. Cracks appear at the hot spot stress location of these joints and it can be due to fatigue, damage from impacts and dropped objects, improper design and corrosion damage [1]. Hot spot stress is located at the corner of the weld toe which is at the brace to chord intersection region of SHS joints. The challenging issue faced by the researchers is to accurately model the crack region of any tubular joint. Cheaitani and Burdekin [2] carried out the assessment of the effects of cracks on the plastic collapse load $\left(P_{\mathrm{c}}\right)$ and fracture behaviour of CHS K-joints. They recommended that conservative estimate of $P_{\mathrm{c}}$ load of cracked CHS K-joints can be obtained by multiplying the strength of the uncracked joints by a reduction factor $\left(F_{\mathrm{AR}}\right)$. The $F_{\mathrm{AR}}$ expression takes care of the decrease in $P_{\mathrm{c}}$ load brought about by the presence of cracks. They have proposed the following expression for $F_{\mathrm{AR}}$ 
which is also incorporated in BS 7910:2013+A1:2015 [3], Guide to Methods for Assessing the Acceptability of Flaws in Metallic Structures (hereafter referred to as 'The Guide'), and it is expressed as,

$$
F_{\mathrm{AR}}=\left[1-\frac{\text { crack area }}{\text { weld length } * \text { chord thickness }}\right]\left[\frac{1}{Q_{\beta}}\right]^{m_{\mathrm{q}}}
$$

where $Q_{\beta}$ is the geometrical modifier which depends on brace to chord width ratio $(\beta)$ values, and it is expressed as

$Q_{\beta}=1$, for $\beta \leq 0.6$

$Q_{\beta}=\frac{0.3}{[\beta(1-0.833 \beta)]}$, for $\beta>0.6$

For tubular joints containing part-thickness flaws, $m_{\mathrm{q}}=0$ and for tubular joints containing through-thickness flaws, $m_{\mathrm{q}}=1$. The existing equation for $F_{\mathrm{AR}}$ was developed from parametric study carried out for CHS joints and it may not be applicable for SHS joints. Even for CHS Xjoints, Wang et al. [4] proposed the following equation for determining $F_{\mathrm{AR}}$ of cracked CHS Xjoints;

$$
F_{\mathrm{AR}}=\left(1-\frac{A_{\mathrm{c}}}{l_{\mathrm{w}} * t_{0}}\right) * 0.8-0.28
$$

where $A_{\mathrm{c}}$ is the crack area, $l_{\mathrm{w}}$ is the weld length and $t_{0}$ is the chord thickness. Additionally, Qian [5] observed that $F_{\mathrm{AR}}$ has a significant effect on the failure assessment curve of CHS X- and Kjoints.

From the above equations, it can be seen that there is a need to optimize the $F_{\mathrm{AR}}$ equations for cracked SHS joints. The previous works also pointed to the need of carrying a wider extensive parametric study covering various types of joints as well as a broader set of parameters. Furthermore, it is mentioned in 'The Guide' [3] that for CHS tubular joints containing part- 
thickness flaws (surface cracks), the $m_{\mathrm{q}}$ value is equal to zero. Therefore, the $\left(\frac{1}{Q_{\beta}}\right)^{m_{\mathrm{q}}}$ term from equation (1) will become one signifying that the ' $\beta$ ' has no effect in the calculation of $F_{\mathrm{AR}}$ for cracked CHS tubular joints. However, the present parametric study shows that the $\beta$ has an influence on the $F_{\mathrm{AR}}$ values for cracked SHS K-joints containing surface cracks. So in order to optimize the equation for SHS joints, the present study carries out extensive parametric study of cracked SHS K-joints to propose new $F_{\mathrm{AR}}$ equations for these joints. The new $F_{\mathrm{AR}}$ equations for cracked SHS T-joints are already published by the authors [6].

\section{Full scale experimental tests on SHS K-joints}

In order to achieve the research objectives, a completely new and robust finite element (FE) mesh generator is developed in this study. The newly developed automatic FE mesh generator is validated using the full scale experimental test results as well as with the existing commercial software results $[6,7,8,9,10]$. This section describes the full scale experimental tests carried out on SHS K-joints. The conventional dimensional notations used in the SHS K-joints are given in Fig. $1[11,12]$. A specifically designed test rig as shown in Fig. 2 is used to test the cracked SHS K-joints. The ends of the chord are fixed with the yellow rig as shown in Fig. 2. The load is applied on the end of the brace through the spread beam which is supported by two hydraulic jackets (Fig. 3). Each hydraulic jacket can produce $1000 \mathrm{kN}$ load.

Elastic loading is performed prior to the test to inspect the operation of the different gauges, Linear Variable Displacement Transducers (LVDTs) and the output of the actuator. The specimen is loaded to $3 \%$ of the projected total capacity, and then unloaded to make sure that the instrumentation readings resumed to zero acceptably. Fig. 4 depicts the recording system during the testing process. The measurements of the strain gauges and LVDTs are recorded by the data logger and they are monitored visually by the computer. The axial tensile load is applied at the brace end through displacement control. The tests are considered complete when the joint failed completely, when the loads taken by the specimens dropped substantially. 
The brace end displacement is acquired from an LVDT with a stroke capacity of $50 \mathrm{~mm}$ which is calibrated and fixed to the lower part of spread beam in alignment with the centreline of the brace. The load is attained via load cell of the actuators, and is also measured by means of strain gauges fixed at the middle of the brace to verify the load readings.

The specimens are fabricated using BS4360 structural steel of grade 50D. Each specimen contains one fatigue surface crack below the weld toe. The length of crack is $125 \mathrm{~mm}$ with one part of $37 \mathrm{~mm}$ and the other being $88 \mathrm{~mm}$. The crack depth is $4.9 \mathrm{~mm}$ for the specimen while the width of the weld is chosen as $8 \mathrm{~mm}$. The mechanical properties of the BS4360-50D steel supplied by the manufacturer, Corus, in UK, are as follows; the yield strength of $380.3 \mathrm{MPa}$, the tensile strength of $529 \mathrm{MPa}$, the Charpy $\mathrm{V}$-notch temperature of $-20^{\circ} \mathrm{C}$ and the Charpy V-notch energy of 170 joules. American Welding Society (AWS) Structure Welding Code D1.1-2000 [13] specifications are used for the weld profile. Ultrasonic inspection was used to guarantee the weld quality. The welding electrodes are E70XX type conforming to AWS D1.1-2000 [13]. The mechanical properties of the weld are as follows; the yield strength of $399.9 \mathrm{MPa}$ and the tensile strength of $482.6 \mathrm{MPa}$. The comparison of the yield stress of the weld material with the parent material yield stress of $380.3 \mathrm{MPa}$ revealed only $5 \%$ difference. Hence, the weld material is found to match the parent material.

Fig. 5 illustrates the crack surfaces of the specimens produced. The ductile tearing, fatigue surface and brittle fracture surface are clearly demarcated in the depicted plot. It reveals that the ductile tearing has occurred near a small region adjacent to the crack tips. The shiny and smooth natures of the fracture surfaces around the deepest point of the cracks indicate the occurrence of brittle cleavage fracture. In the final failure of the SHS K-joint, the intersection of brace to chord breaks (Fig. 6). The findings from the above mentioned experimental tests are important to check the validity and accuracy of the new FE mesh generator and it is covered in the following section. 


\section{Parametric study on SHS K-joints}

As mentioned in the previous section, a completely new and robust finite element (FE) mesh generator is developed to carry out parametric study of the cracked SHS K-joints $[6,7,8,9,10]$. It can be effectively used to generate FE mesh models such as plate joints with both symmetrical and unsymmetrical cracks, plate-to-plate welded joints such as T-butt joints with single-sided and double-sided welds and cruciform X-joints. Regarding hollow section joints, it can be used to model uncracked and cracked uni-planar SHS T-, Y- and K-joints, and uncracked and cracked multi-planar SHS TT-, YT- and KT-joints. The new FE mesh generator is able to overcome the drawbacks of the previous mesh generating approaches by demonstrating the capability of achieving convergence of solutions even at a very high plastic deformation. It is versatile enough to model cracks of any arbitrary dimensions. The concept of using key-hole for elasticplastic analysis is effectively incorporated in the new FE mesh generator. The usage of only one type of element, a 20 nodes hexahedral element, eliminates the compatibility issues associated with the mesh modelling. The "spider web" configuration which is the most efficient mesh design for the crack tip region enables a smooth conversion from a fine mesh at the crack tip region to a coarser mesh away from high stress concentration region. Mesh refinement and zoning techniques are extensively used in the new FE mesh generator so that it is robust enough to model different types of uni-planar and multi-planar SHS welded joints with and without cracks. Another feature of the new FE mesh generator is the fast generation of different types of cracked and uncracked models. For example, a typical cracked SHS K-joint with 20,000 elements can be generated within three minutes.

In the mesh generation procedure, the crack tube and crack block of a flat plate are modelled first and subsequently, transition zones are used to connect the parent crack block with the other parts of the flat plate. The detailed cross-sectional view of the mesh design pattern at crack front is illustrated in Fig. 7. There are obvious advantages in using transition zones in any FE mesh generator. Firstly, it helps to reduce the number of elements in the FE mesh model. This will in 
turn reduce the analysis time of the FE mesh models. The pivotal regions such as crack front can be modelled with FE meshes of high mesh density and the regions that are further away from pivotal regions can be modelled with FE meshes of low mesh density. Secondly, it helps greatly in source code debugging. Errors in models can be spotted and rectified locally due to usage of different sub-zones. In addition, transition zones enable to connect parent crack block with adjacent mesh blocks. The parent brace parts generated is transformed to a complete cracked SHS K-joint by adding the chord parts on both sides (Fig. 8). The number of divisions in both chord and brace parts is kept as a variable in the new FE mesh generator so that the user can conveniently decide the extent of mesh-refinement needed. The refined mesh regions aid in convergence of solutions as well as it enables to capture high stress/strain gradients [14].

Various aspects such as mesh refinement, mesh convergence, aspect ratio check, proper zoning, comparison with the commercial software results and comparison with the full-scale experimental test results are adopted to ensure the quality of the FE mesh used. For example, the $J$-integral results produced using the new FE mesh generator is validated with the solutions obtained from the mesh generated using FEACrack ${ }^{\mathrm{TM}}$ software [15]. Fig. 9 illustrates the comparison of $J$-integral values obtained from FEACrack ${ }^{\mathrm{TM}}$ software [15] as well as from the new FE mesh generator. The maximum percentage difference between both cases is $0.09 \%$ at the deepest point of the crack and $7.89 \%$ at the ends of the crack. The largest $J$-integral values for both cases are located at the deepest point of the crack. The pattern of variation of $J$-integral values with crack front angle values is found to be complementary for both cases. Moreover, there is convergence of values for both cases which confirms the reliability of using the new FE mesh generator. The validation of new FE mesh generator with experimental test results is described in the following section. Similarly, other aspects to ensure the mesh quality are diligently carried out and are also available in other previously published works of the authors $[6,7,8,9,10]$. 


\subsection{Validation of new FE mesh generator with experimental test results}

Fig. 10 displays the load-displacement curves for the $P_{\mathrm{c}}$ load of the SHS K-joint specimen. The elastic region for the experimental curve is up to $600 \mathrm{kN}$. The crack shows an obvious ductile tearing until the load reaches $1115 \mathrm{kN}$, and then the crack propagates through the chord wall thickness. The tendency of the load-displacement curve obtained from numerical analyses being slightly above the experimental curve is most prominent in the case of SHS K-joint. It is attributed to the fact that the stress-strain curve used for numerical analyses may not be exactly same as the actual condition in the full-scale experimental tests. For instance, the stress-strain curve at the corner of the square hollow section is generally higher due to the strain hardening in the corner. Moreover, K-joint has an additional brace component when compared to SHS T- and Y-joints; thereby the above mentioned reason is all the more valid.

The post-peak unloading curves observed in the numerical simulations are not following the unloading paths in the experimental results. The scope of the research is focused on plasticcollapse analyses of the SHS K-joints. In the numerical analysis, crack fracture and propagation are not taken into account. Therefore, the load displacement curves from FE analysis behave as continuously increasing without showing a peak value. For the load displacement curves obtained from experimental testing, a peak value is observed due to the crack fracture and propagation. These two trends are not in conflict. There is good agreement with the experimental and numerical results for load-displacement curves in the plastic-collapse region. Hence, the numerical models created using the new FE mesh generator are accurate and slightly conservative in terms of $P_{\mathrm{c}}$ load values, and it can be used to carry out extensive parametric study of cracked SHS K-joints. The von Mises stress distributions of cracked SHS K-joint at $P_{\mathrm{c}}$ load of $971.80 \mathrm{kN}$ is illustrated in Fig. 11. Chord face plastification failure mode is observed for the joint which has the brace to chord width ratio $(\beta)$ equal to 0.50 . 


\subsection{Parameters used in the parametric study}

Extensive study is carried out to investigate the effect of two parameters, brace to chord width ratio $(\beta)$ and crack area, on the reduction factor $\left(F_{\mathrm{AR}}\right)$ of cracked SHS K-joints. The $P_{\mathrm{c}}$ load formulae for the uncracked SHS K-joints are given by Eurocode 3 [16],

$$
N_{1, \mathrm{RD}}=\frac{8.9 \beta \gamma^{0.5} k_{\mathrm{n}} f_{\mathrm{y} 0} t_{0}^{2}}{\sin \theta_{1}} / \gamma_{\mathrm{MS}}
$$

where

$N_{1, \mathrm{RD}}=$ design axial resistance of the welded joint

$k_{\mathrm{n}}=1.0 \quad$ for $\mathrm{n} \leq 0$ (tension)

$k_{\mathrm{n}}=1.3-\frac{0.4}{\beta} \mathrm{n} \quad$ for $\mathrm{n}>0$ (compression) but $k_{\mathrm{n}} \leq 1.0$

$f_{\mathrm{y} 0}=$ specified design yield strength

$\theta_{1}=$ the angle between brace member and the chord

$\gamma_{\mathrm{M} 5}=$ resistance of joints in hollow section lattice girder $=1.0$

As mentioned before, the $P_{\mathrm{c}}$ load of a cracked SHS K-joint can be obtained by multiplying equation (5) by a reduction factor $\left(F_{\mathrm{AR}}\right)$. The crack area refers to the cross-sectional area of the crack and it is given by the sum of the areas of two half semi-ellipses. The parameter 'crack area factor' represents the percentage of crack area with respect to the total cross-sectional area. From equation (1), it can be seen that the total cross-sectional area is obtained by multiplying total weld length with the chord thickness. For example, a 'crack area factor' of $10 \%$ implies that the value of $\left(\frac{\text { crack area }}{\text { weld length } * \text { chord thickness }}\right) * 100 \%$ is equal to $10 \%$. 11 different values of $\beta$ are analyzed for percentage crack area values of $5.8 \%, 10 \%, 20 \%$ and $0 \%$. The values of $\beta$ vary from a lower limit of 0.25 to a higher limit of 0.75 . Stacey et al. [17] suggested that for nullifying the chord length to half chord width ratio $(\alpha)$ effect, a minimum $\alpha$ value of 8 should be used. It was also suggested that the chord length should be at least four times the 
chord diameter. The current parametric study fulfils both the above suggestions, and hence the effect of $\alpha$ can be ignored. It was further suggested that, chord half width to thickness ratio $(\gamma)$ does not have a substantial effect on the $P_{\mathrm{c}}$ load for $\beta$ up to 0.8 . Therefore, the emphasis of current research is towards the effect of $\beta$ and the crack area on the reduction factor $\left(F_{\mathrm{AR}}\right)$ for cracked SHS K-joints.

As stated before, the research is carried out on BS4360 structural steel of grade 50D, and the stress-strain curve of the material is shown in Fig. 12. The Young's modulus and Poisson's ratio of the material used are $210 \mathrm{kN} / \mathrm{mm}^{2}$ and 0.3 respectively. Axial loads are applied to the one brace end while the other brace end and the chord ends are fixed (Fig. 13). For all the cases considered in the present study, the chord length is fixed at a value of $3000 \mathrm{~mm}$. The longer value of chord length used guarantees that the effect of chord end boundary conditions on the failure of damaged joints is insignificant $[18,19]$.

\section{Results and discussion}

The commercial FE software, ABAQUS [20] is used to analyse the automatically generated input files (models) from the new FE mesh generator. There are two options to apply loading in ABAQUS [20], through load-control and displacement control. The current study uses displacement control whereby the steadily increasing displacement values are applied to the brace end, which are comparable to applying steadily increasing load values. In the final stage, the load-displacement curves are produced for each model and resultant calculations are performed. A typical load-displacement curve obtained from the present study for SHS K-joint is depicted in Fig. 14. It shows the load-displacement behaviour for both cracked and uncracked SHS K-joints $(\beta=0.5$, crack area $=5.8 \%)$. The presence of crack reduces the load-carrying capacity of the SHS K-joint. For crack area of 5.8\%, $10 \%$ and 20\%, the load-displacement curves for SHS K-joints are shown in Figs. 15 to 17. Brace end axial loading values are represented along the ordinate while the brace end displacements are plotted along the abscissa. 
One common observation from the plots for different crack areas is that the characteristic strength of the SHS K-joints rises with the increasing value of $\beta$.

\subsection{Determination of plastic collapse loads}

The methodology used in the current research for estimating the plastic-collapse $\left(P_{\mathrm{c}}\right)$ load of SHS K-joints is the twice-elastic compliance (TEC) criterion. Previous studies have used the TEC criterion extensively to determine the $P_{\mathrm{c}}$ load of cracked tubular joints $[21,22,23]$. In the ASME rules for construction of pressure vessels [24], this criterion is expressed as the twiceelastic slope (TES) criterion. It is based on the load-deformation response of a structure in the plastic analysis as depicted in Fig. 18. The $P_{\mathrm{c}}$ load is determined as the load corresponding to the junction of the load-deformation curve and the twice elastic compliance line. The twice elastic compliance line begin from the origin of the load-deformation curve and has twice the slope of the initial elastic response, which is attained using the equation

$\tan \varphi=2 \tan \theta$

where $\varphi$ and $\theta$ are the angles measured from the load axis as shown in Fig. 18. Subsequently, the reduction factor $\left(F_{\mathrm{AR}}\right)$ is calculated using the following equation:

$F_{\text {AR }}=\frac{\text { Plastic collapse load of cracked SHS K - joint }}{\text { Plastic collap se load of uncracked SHS K - joint }}$

\subsection{Effect of brace to chord width ratio $(\beta)$ and crack area}

Contrary to reduction factor $\left(F_{\mathrm{AR}}\right)$ of CHS joints comprising part-thickness cracks in 'The Guide' [3], the current research reveals that $\beta$ has an effect in $F_{\mathrm{AR}}$ for cracked SHS K-joints (Fig. 19). For a specific crack area, $F_{\mathrm{AR}}$ diverges from $1.7 \%$ to $3.6 \%$ for various values of $\beta$. Comparison of the $F_{\mathrm{AR}}$ values for SHS K-joints with values obtained from 'The Guide' [3] reveals that the latter is conservative up to $9 \%$ for crack area of $5.8 \%$, and up to $23.5 \%$ for crack area of $20 \%$. Regarding the mode of failures for cracked SHS K-joints, punching shear failure 
mode is observed for low $\beta$ values $(<0.5)$ and chord face plastification failure mode is observed for high $\beta$ values $(\geq 0.5)$. The choice is based on the observations from the parametric study carried out for the current research work. There is noticeable deformation/bending of chord face in the case of chord face plastification failure mode of SHS K-joints. In addition there is an increase of $F_{\mathrm{AR}}$ is observed with increasing $\beta$ values for chord face plastification failure mode which is different to the trend observed for $F_{\mathrm{AR}}$ values of cracked CHS joints estimated using the 'The Guide' [3] equation. As mentioned previously, the $F_{\mathrm{AR}}$ values calculated using 'The Guide' [3] equation do not change with varying values of $\beta$.

The parameter which has the most influence on the $F_{\mathrm{AR}}$ values is the crack area. It is observed that the $P_{\mathrm{c}}$ load of the cracked SHS K-joints decreases with the increasing crack size. As a result, the $F_{\mathrm{AR}}$ values calculated using the equation (9) is reduced, which signifies the reduction in strength of SHS K-joints caused by increasing crack size. Figs. 20 and 21 shows the comparison of $F_{\mathrm{AR}} \mathrm{vs}$ crack area plot for punching shear failure mode and chord face plastification failure mode, respectively. The results specify that the $F_{\mathrm{AR}}$ varies from $2.3 \%$ to $5.7 \%$ for different values of crack area for cracked SHS K-joints.

\subsection{New reduction factor equations for cracked SHS K-joints}

From the previous sections it is evident that the $F_{\mathrm{AR}}$ varies non-linearly with $\beta$ and the crack area for SHS K-joints. Therefore, non-linear regression techniques are used in curve fitting the numerical data obtained from the parametric study. For the two sets of failure mode of SHS Kjoints, the following equations are proposed;

$$
\begin{aligned}
& \text { For } \beta \geq 0.5 ; F_{\mathrm{AR}}=\left(1-\frac{A_{\mathrm{c}}}{l_{\mathrm{w}} * t_{0}}\right)^{0.21} * \beta^{0.03} * 1.02 \\
& \text { For } \beta<0.5 ; F_{\mathrm{AR}}=\left(1-\frac{A_{\mathrm{c}}}{l_{\mathrm{w}} * t_{0}}\right)^{0.10} * \beta^{-0.03} * 0.97
\end{aligned}
$$


where $A_{\mathrm{c}}$ is the crack area, $l_{\mathrm{w}}$ is the weld length and $t_{0}$ is the chord thickness.

The coefficient of determination values for the proposed equations are 0.980 and 0.942 . These high values for the non-linear regression substantiate the statistical accuracy of the proposed equations. The focal point of this study is to carry out parametric study of SHS K-joints with surface cracks located at the hot spot stress region and to propose a new equation for reduction factor $\left(F_{\mathrm{AR}}\right)$. To ensure continuity of the proposed equations, plots are made showing the variation of $F_{\mathrm{AR}}$ for $\beta$ at 0.49 and at 0.50 . The plotted trends are shown in Fig. 22 and the plots reveal that there is good continuity for the proposed equations.

\section{Conclusions}

A completely new and robust finite element (FE) mesh generator is developed in the current research to carry out parametric study of the cracked SHS K-joints. The newly developed automatic FE mesh generator is validated using the full scale experimental test results as well as with the existing commercial software results. The effect of two parameters, $\beta$ and crack area, on the $F_{\mathrm{AR}}$ of cracked SHS K-joints is investigated. For a specific crack area, $F_{\mathrm{AR}}$ fluctuates from $1.7 \%$ to $3.6 \%$ for various values of $\beta$. Comparison of the $F_{\mathrm{AR}}$ values for SHS K-joints with values obtained from 'The Guide' [3] reveals that the latter is conservative up to $9 \%$ for crack area of $5.8 \%$, and up to $23.5 \%$ for crack area of $20 \%$. The parameter which has the most influence on the $F_{\mathrm{AR}}$ values is the crack area. It is observed that the $P_{\mathrm{c}}$ load of the cracked SHS $\mathrm{K}$-joints decreases with the increasing crack size. The results shows that the $F_{\mathrm{AR}}$ varies from $2.3 \%$ to $5.7 \%$ for different values of crack area for cracked SHS K-joints. Finally, non-linear regression techniques are used in curve fitting the numerical data obtained from the parametric study and new $F_{\mathrm{AR}}$ equations for cracked SHS K-joints are proposed.

\section{Acknowledgements}

The authors would like to thank Maritime Research Centre in the School of Civil and Environmental Engineering at Nanyang Technological University, Singapore, and Maritime Port 
Authority of Singapore for funding this research project under the Grant No. MPA 23/04.15.03 - RDP 005/06/031.

\section{References}

[1] Sharp JV. Ageing offshore structures: A review of recent UK research. Proc. 11th Int Conf Offshore Mech Arctic Engng, Calgary, Canada 1992, pp. 391-398.

[2] Cheaitani MJ, Burdekin FM. Ultimate strength of cracked tubular joints.Tubular structures VI. Proc. 6th Int symp on tubular structures, Melbourne, Australia 1994, pp. $607-616$.

[3] BS 7910:2013+A1:2015. Guide to methods for assessing the acceptability of flaws in metallic structures, British Standards Institution, London, UK, 2015.

[4] Wang X, Wu JF, Qian XD. Crack driving force and ultimate strength of thick-walled CHS X-joints with near-toe cracks. Proc 21st Int Offshore and Polar Eng Conf, Maui, Hawaii, USA 2011, pp. 39-44.

[5] Qian XD. Failure assessment diagrams for circular hollow section X- and K-joints. Intl J of Pressure Vessels and Piping (2013) 104:43-56.

[6] Lie ST, Vipin SP, Li T. New reduction factor for cracked square hollow section T-joints under axial loading. J Constr Steel Res (2015) 112:221-227.

[7] Lie ST, Vipin SP, Li T. New weld toe magnification factors for semi-elliptical cracks in double-sided T-butt joints and cruciform X-joints. Int J of Fatigue (2015) 80:178-191.

[8] Vipin SP. Safety and risk assessment of damaged multi-planar square hollow section (SHS) TT-, YT- and KT-joints. Ph.D. dissertation, Nanyang Technological University, Singapore, 2015.

[9] Lie ST, Zhao HS, Vipin SP. New weld toe magnification factors for semi-elliptical cracks in plate-to-plate butt-welded joints. Fatigue Fract Eng Mater Struct (2016) 00:01-13. 
[10] Vipin SP, A Kolios, Lie ST. Failure assessment of cracked uni-planar square hollow section T-,Y- and K-Joints using the new BS 7910:2013+A1:2015. Proc. Int Conf on structural integrity and durability, Dubrovnik, Croatia 2017, pp. 155-156.

[11] IIW. Static design procedure for welded hollow section joints - recommendations. Int Inst of Welding, IIW Doc. XV-1329-09, IIW Doc. XV-E-09-400, 2005.

[12] Packer JA, Wardenier J, Zhao XL, van der Vegte GJ, Kurobane Y. Design guide for rectangular hollow section (RHS) joints under predominantly static loading. $2^{\text {nd }}$ ed. CIDECT 3, Geneva,Switzzerland, 2009.

[13] AWS D1.1-00. Structural welding code: steel. American Welding Society (AWS), USA, 2000.

[14] Brunesi E, Nascimbene R, Rassati GA. Response of partially-restrained bolted beam-tocolumn connections under cyclic loads. J Constr Steel Res (2014) 97:24-38.

[15] FEACrack ${ }^{\mathrm{TM}}$. User's manual, Version 3.2, Quest Integrity Group LLC., USA, 2010.

[16] Eurocode 3: design of steel structures-part 1-8: design of joints, British Standard Institute, UK, 2005.

[17] Stacey A, Sharp JV, Nichols NW. The influence of cracks on the static strength of tubular joints. Proc. 15th Int Conf Offshore Mech Arctic Eng, Florence, Italy 1996, pp. $435-450$.

[18] Lie ST, Lee CK, Chiew SP, Shao YB. Mesh modeling and analysis of cracked uniplanar tubular K-joints. J Constr Steel Res (2005) 61:235-264.

[19] Lie ST, Yang ZM. Plastic collapse load of cracked square hollow section T-, Y-, and Kjoints. J. Offshore Mech.Arct. Eng. (2010) 133:1-10.

[20] ABAQUS. Standard user's manual, Version 6.11, Hibbett, Karlsson \& Sorensen, Inc., USA, 2011.

[21] Stacey A, Sharp JV, Nichols NW. Static strength assessment of cracked tubular joints. Proc. 15th Int Conf Offshore Mech Arctic Engng, Florence, Italy 1996, pp. 211-224. 
[22] Muscat M, Mackenzie D, Hamilton R. A work criterion for plastic collapse. Int J Pres Piping (2003) 80:49-58.

[23] Lie ST, Li T, Shao YB. Plastic collapse load prediction and failure assessment diagram analysis of cracked circular hollow section T-joint and Y-joint. Fatigue Fract Eng Mater Struct (2014) 37:314-324.

[24] ASME VIII Division 2. Rules for construction of pressure vessels. American Society of Mechanical Engineers, USA, 1998. 
Table 1

Table of analyses for crack area factor values of 5.8\%, 10\%, 20\% and $0 \%$

\begin{tabular}{ccccccccc}
\hline$\beta$ & $\gamma$ & $\alpha$ & $\tau$ & $b_{1}$ & $t_{0}$ & $t_{1}$ & $l_{\mathrm{c}}$ & $b_{0}$ \\
\hline 0.25 & 18.8 & 10.0 & 1.0 & 150.0 & 16.0 & 16.0 & 3000.0 & 600.0 \\
0.30 & 15.6 & 12.0 & 1.0 & 150.0 & 16.0 & 16.0 & 3000.0 & 500.0 \\
0.35 & 13.4 & 14.0 & 1.0 & 150.0 & 16.0 & 16.0 & 3000.0 & 428.6 \\
0.40 & 11.7 & 16.0 & 1.0 & 150.0 & 16.0 & 16.0 & 3000.0 & 375.0 \\
0.45 & 10.4 & 18.0 & 1.0 & 150.0 & 16.0 & 16.0 & 3000.0 & 333.3 \\
0.50 & 9.4 & 20.0 & 1.0 & 150.0 & 16.0 & 16.0 & 3000.0 & 300.0 \\
0.55 & 8.5 & 22.0 & 1.0 & 150.0 & 16.0 & 16.0 & 3000.0 & 272.7 \\
0.60 & 7.8 & 24.0 & 1.0 & 150.0 & 16.0 & 16.0 & 3000.0 & 250.0 \\
0.65 & 7.2 & 26.0 & 1.0 & 150.0 & 16.0 & 16.0 & 3000.0 & 230.8 \\
0.70 & 6.7 & 28.0 & 1.0 & 150.0 & 16.0 & 16.0 & 3000.0 & 214.3 \\
0.75 & 6.3 & 30.0 & 1.0 & 150.0 & 16.0 & 16.0 & 3000.0 & 200.0 \\
\hline
\end{tabular}

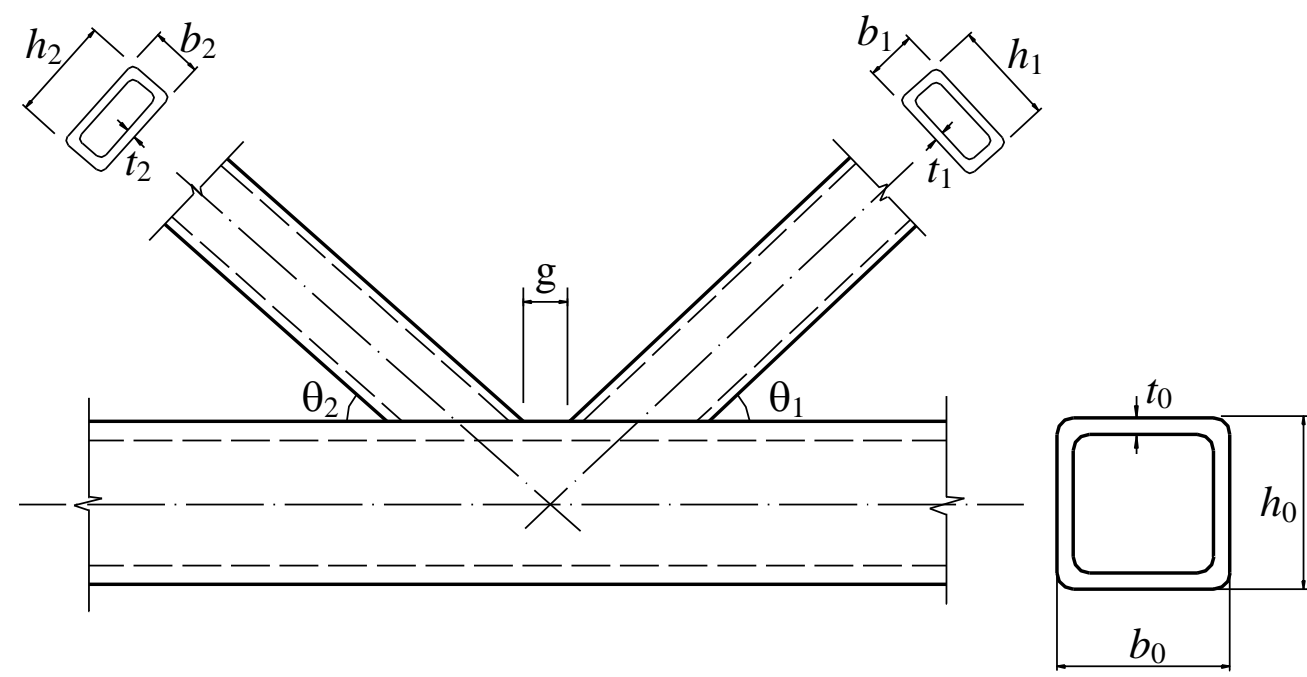

Fig. 1 Dimensional notations used by IIW [11] and CIDECT [12] 


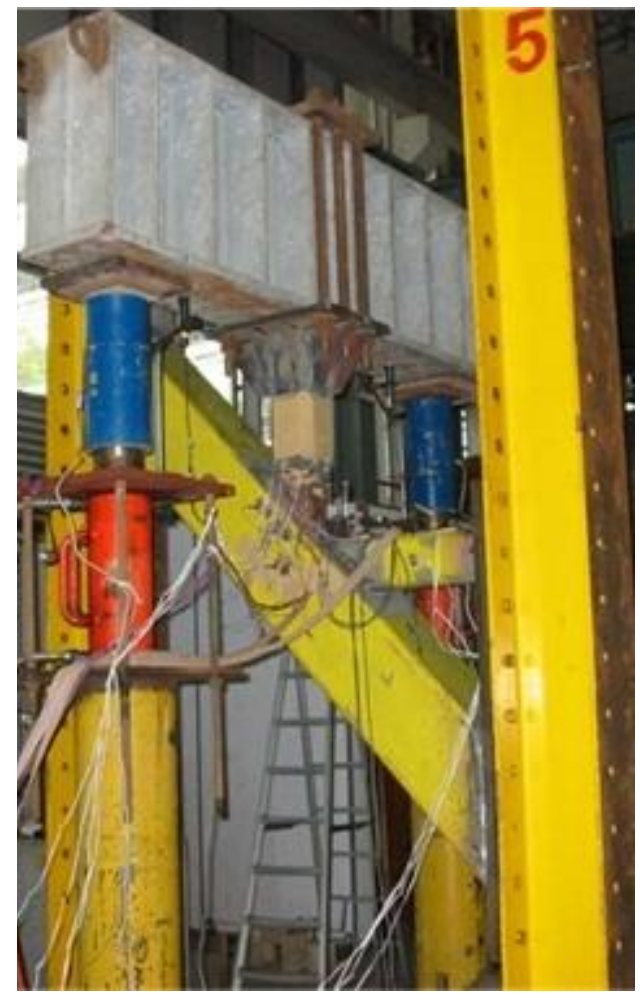

Fig. 2 The experimental test rig for cracked SHS K-joint

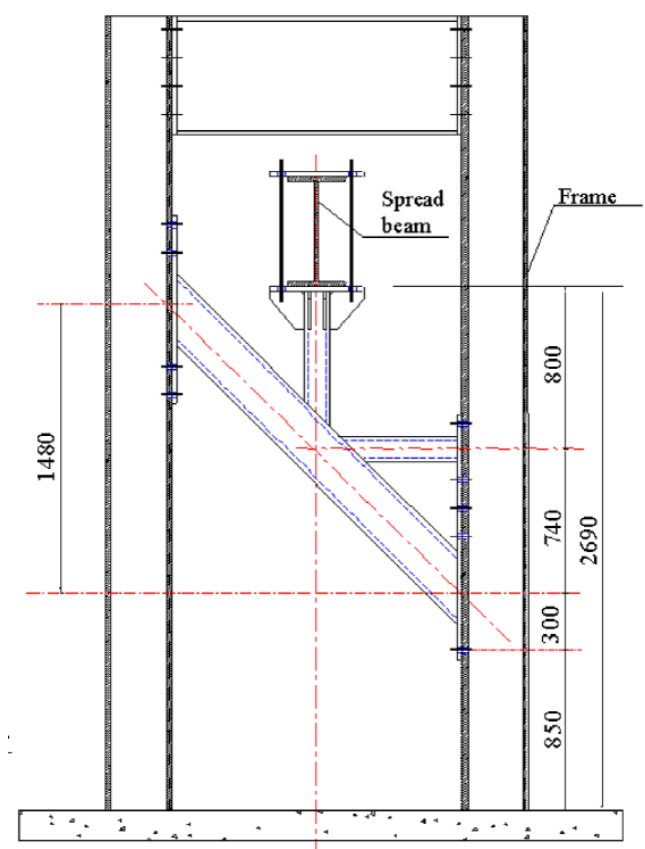

Fig. 3 Schematic view of the test rig used to test the cracked SHS K-joint 


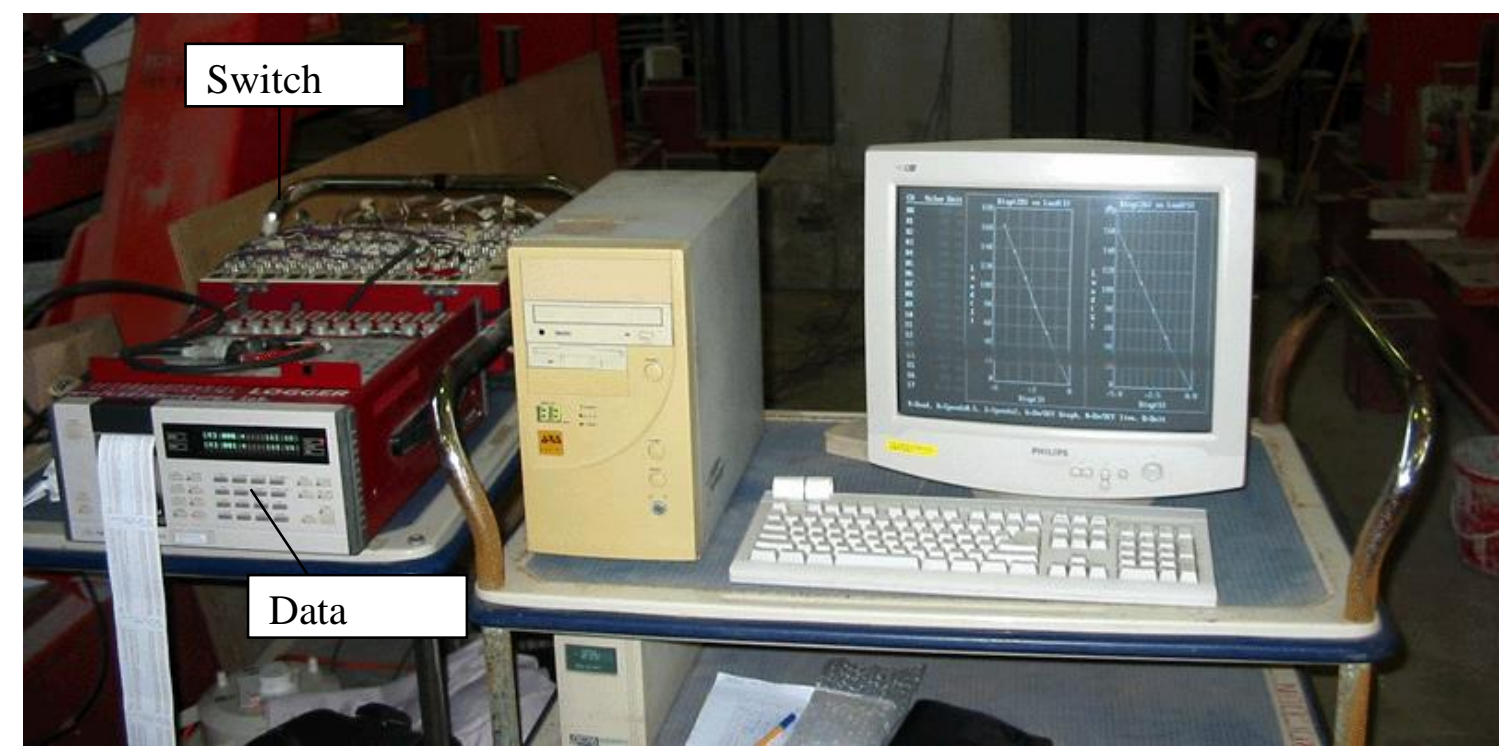

Fig. 4 The recording system set-up used during the test process

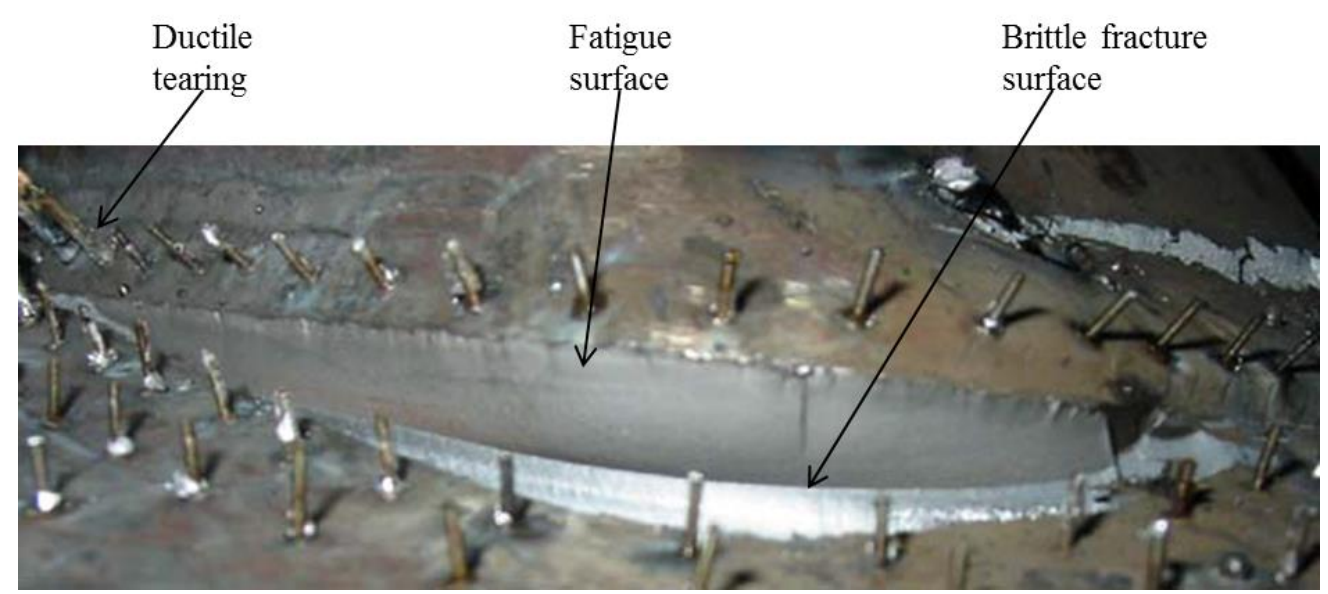

Fig. 5 Fracture surface of K-joint specimen after the tests 


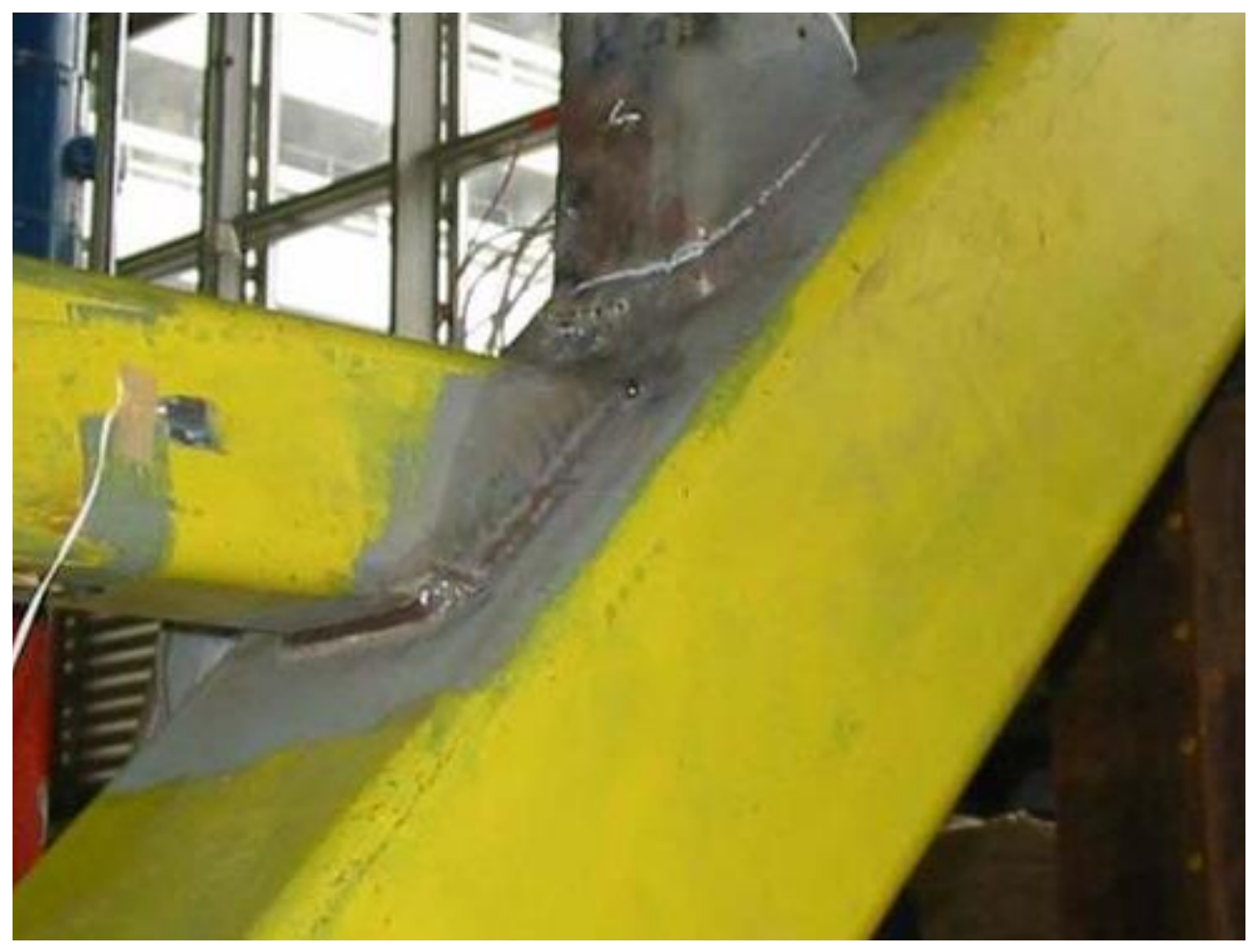

Fig. 6 The final failure of SHS K-joint 

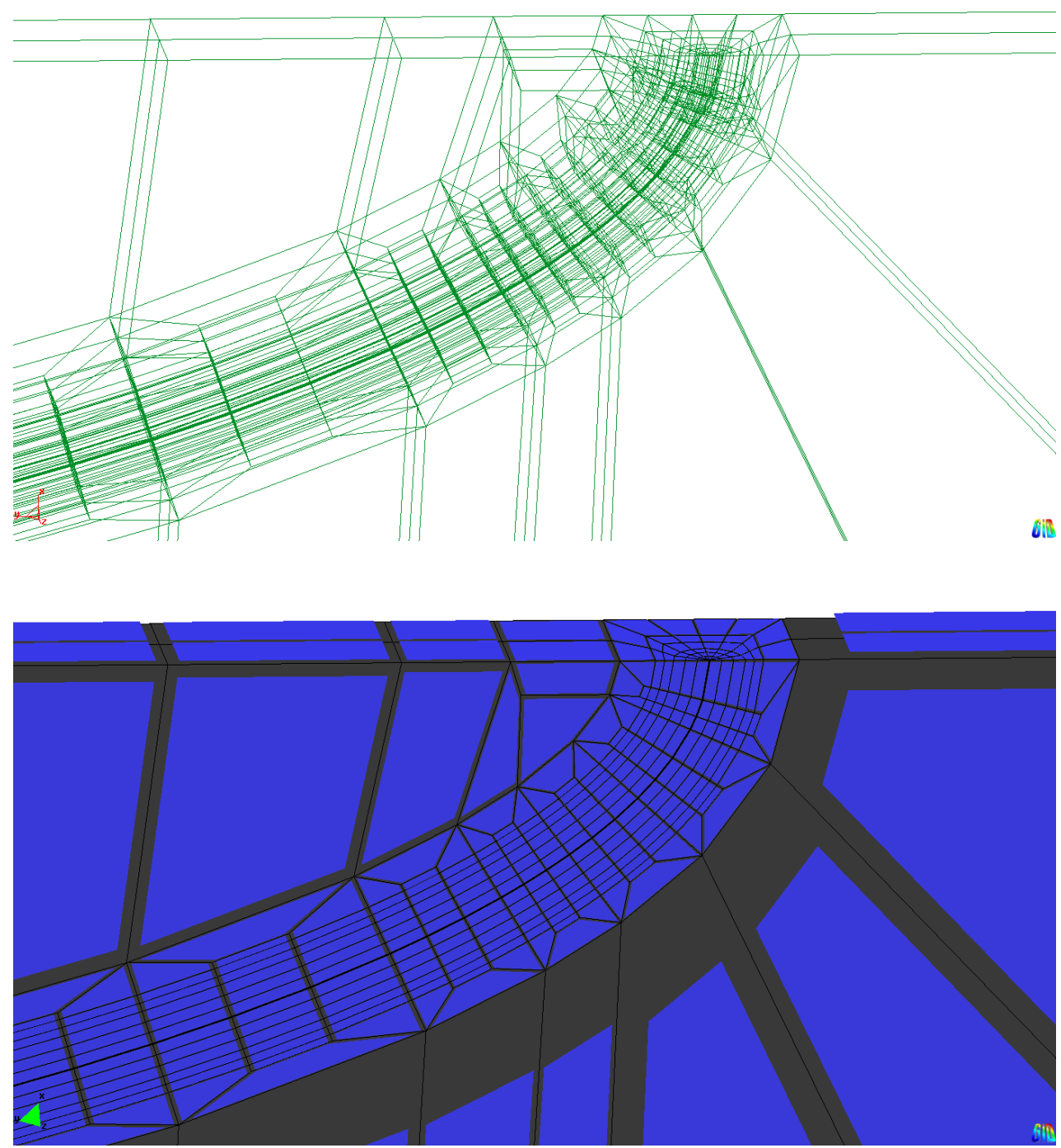

Fig. 7 Sectional view of the mesh design of the crack front 


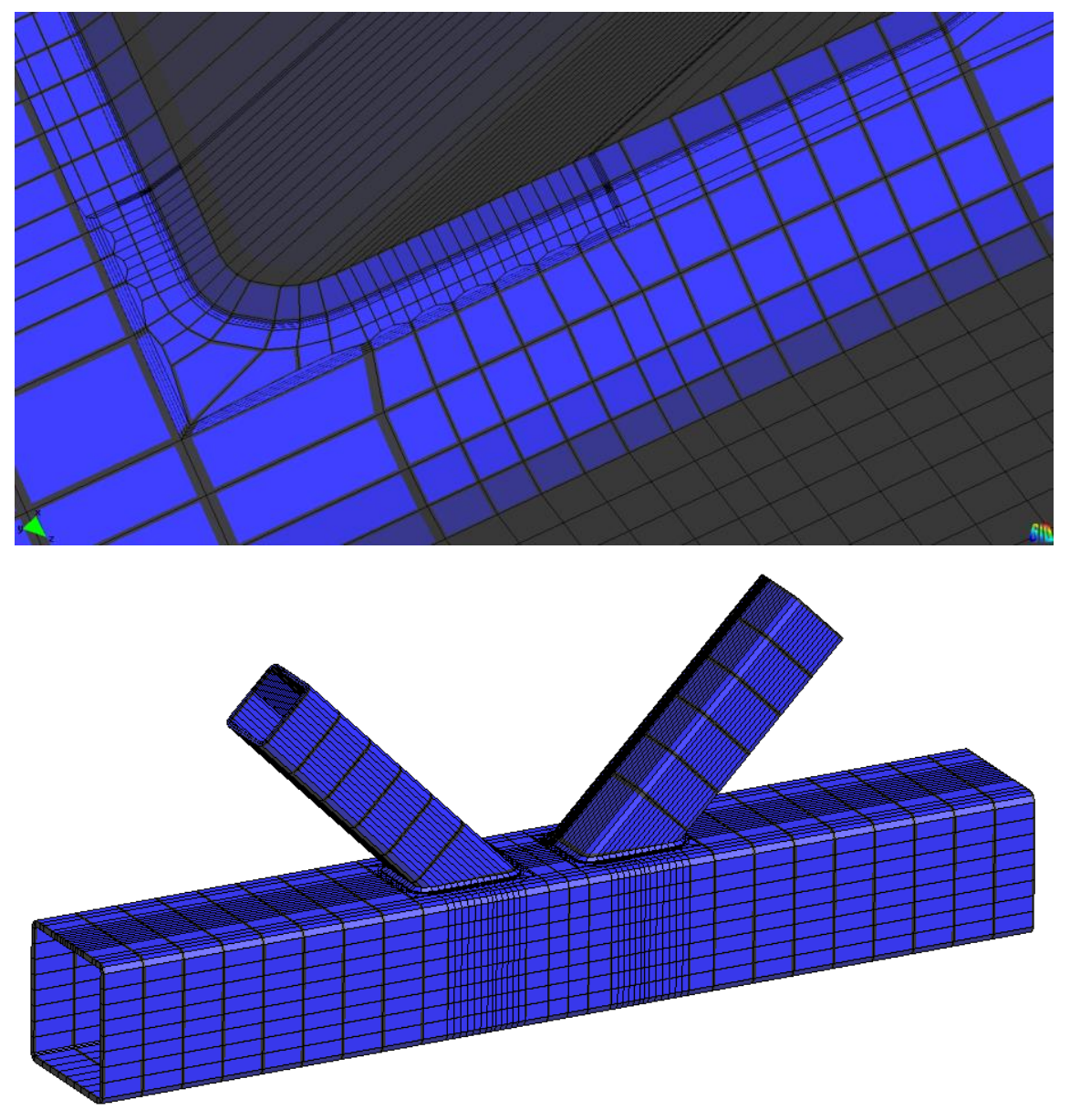

Fig. 8 The completed mesh of a cracked uni-planar SHS K-joint

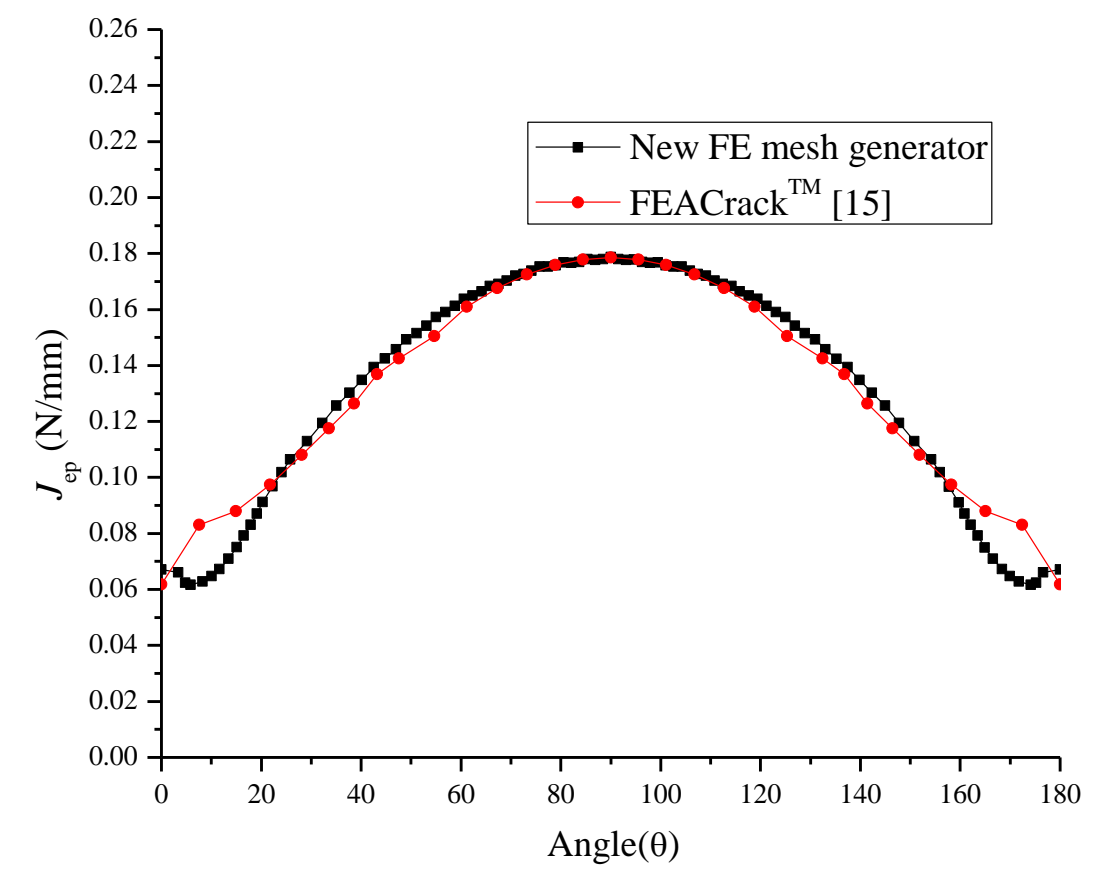

Fig. 9 Comparison of $J$-integral values obtained using new FE mesh generator and FEACrack $^{\mathrm{TM}}$ [15] 


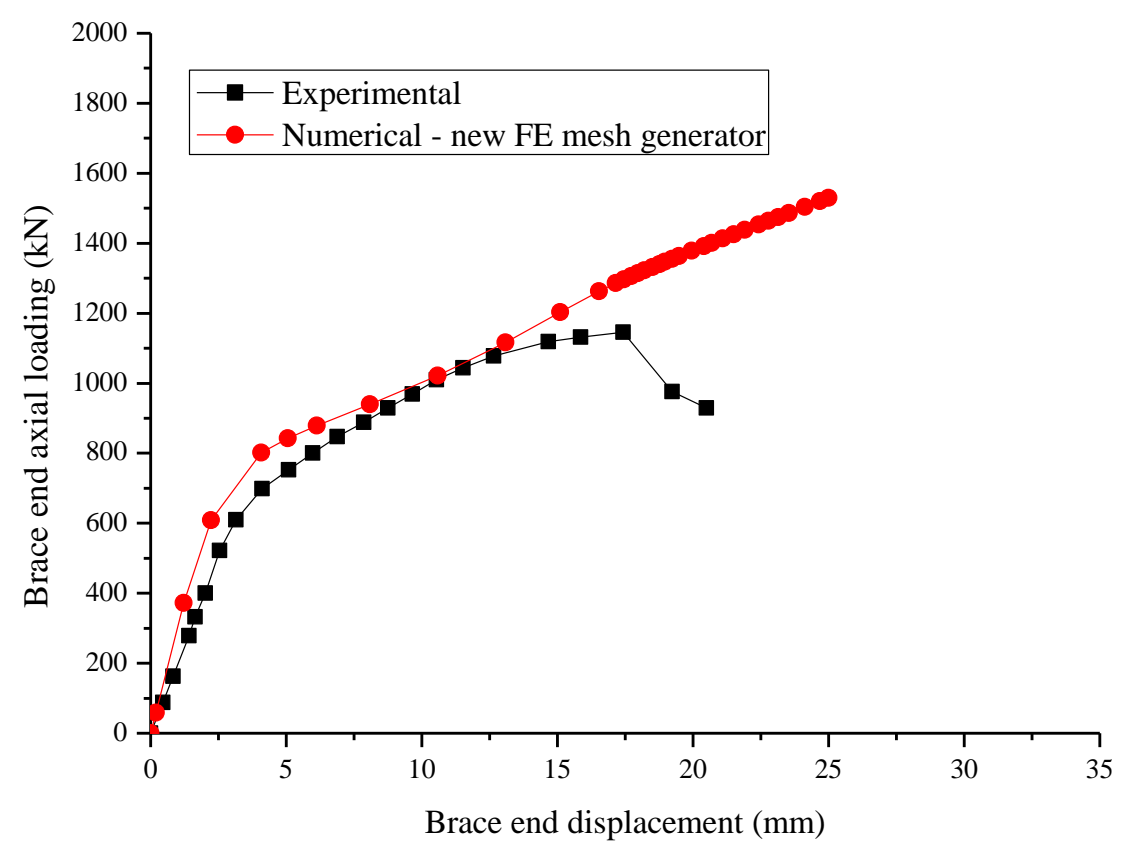

Fig. 10 Comparison of numerical and experimental results for SHS K-joint

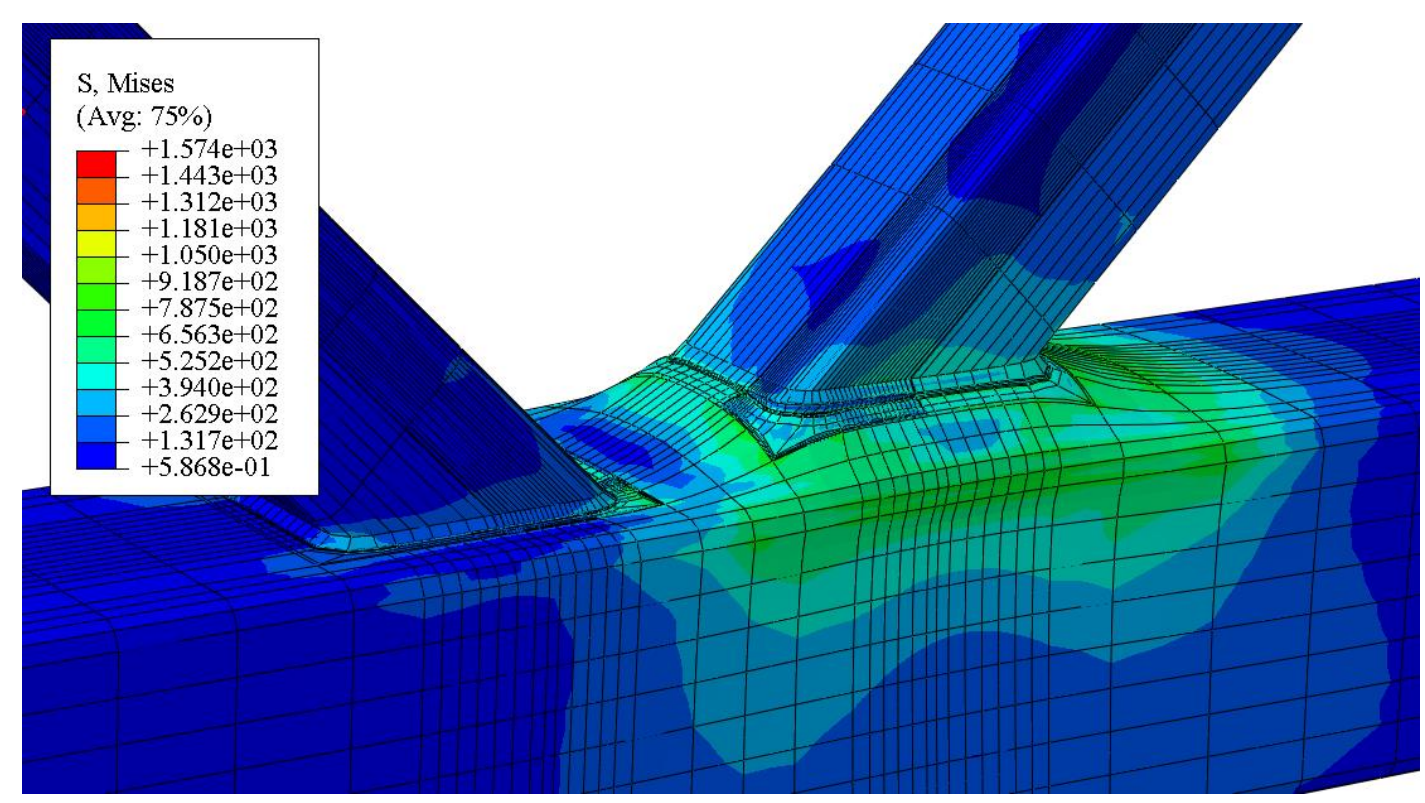

Fig. 11 The von Mises stress distributions of cracked SHS K-joint at $P_{\mathrm{c}}$ load 


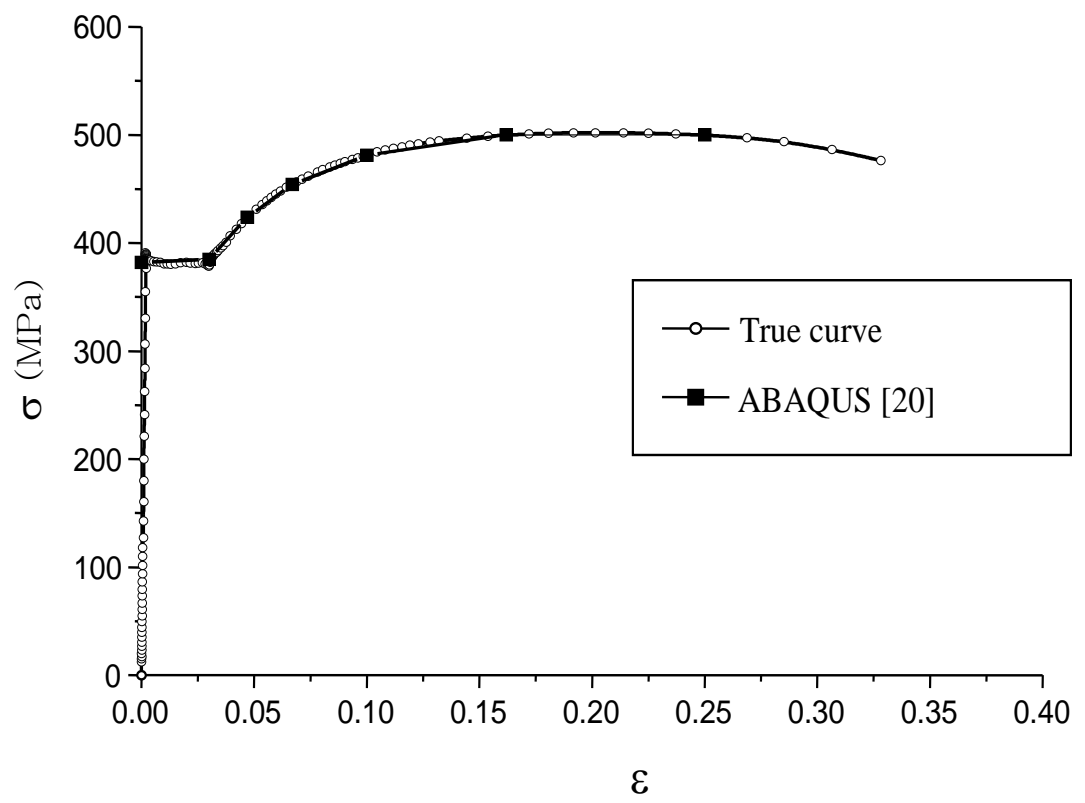

Fig. 12 Stress-strain curve of the BS4360-50D structural steel

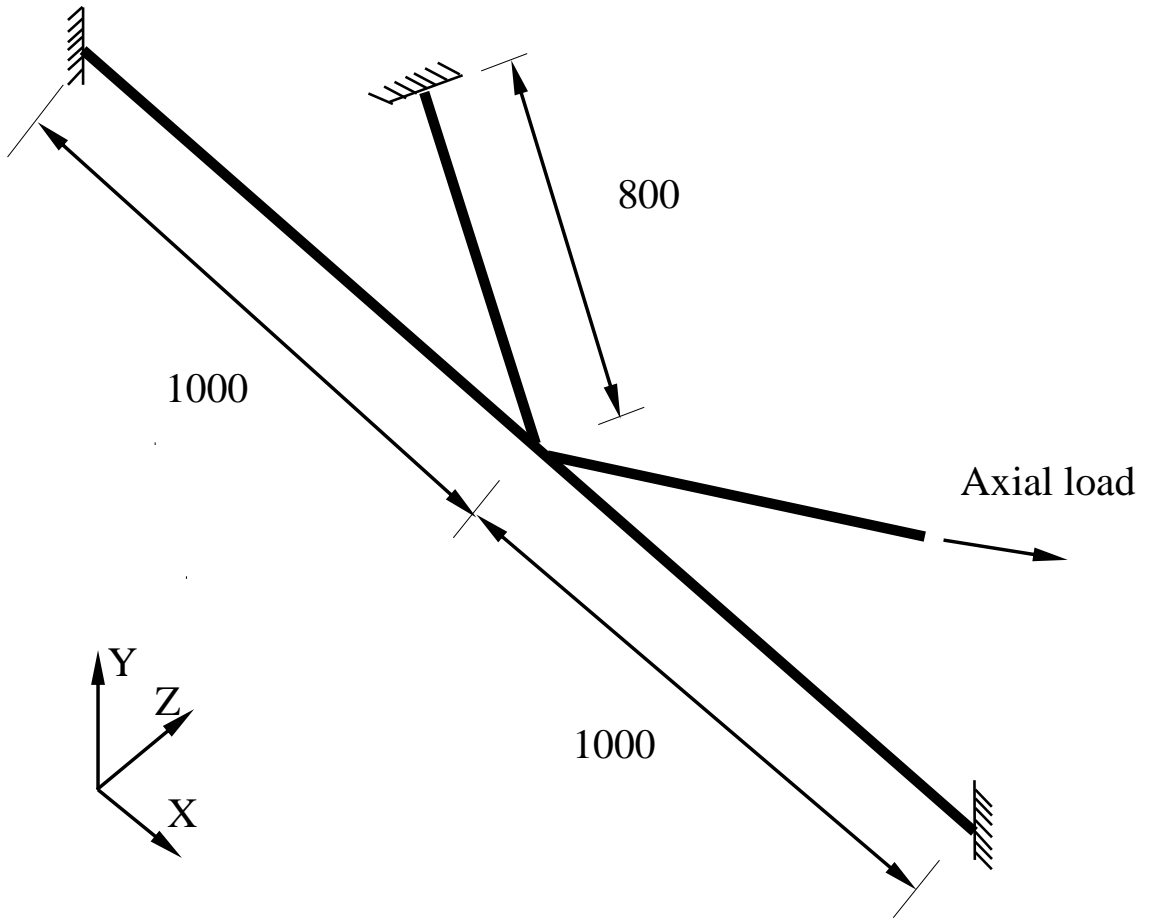

Fig. 13 Loading and boundary conditions for SHS K-joints 


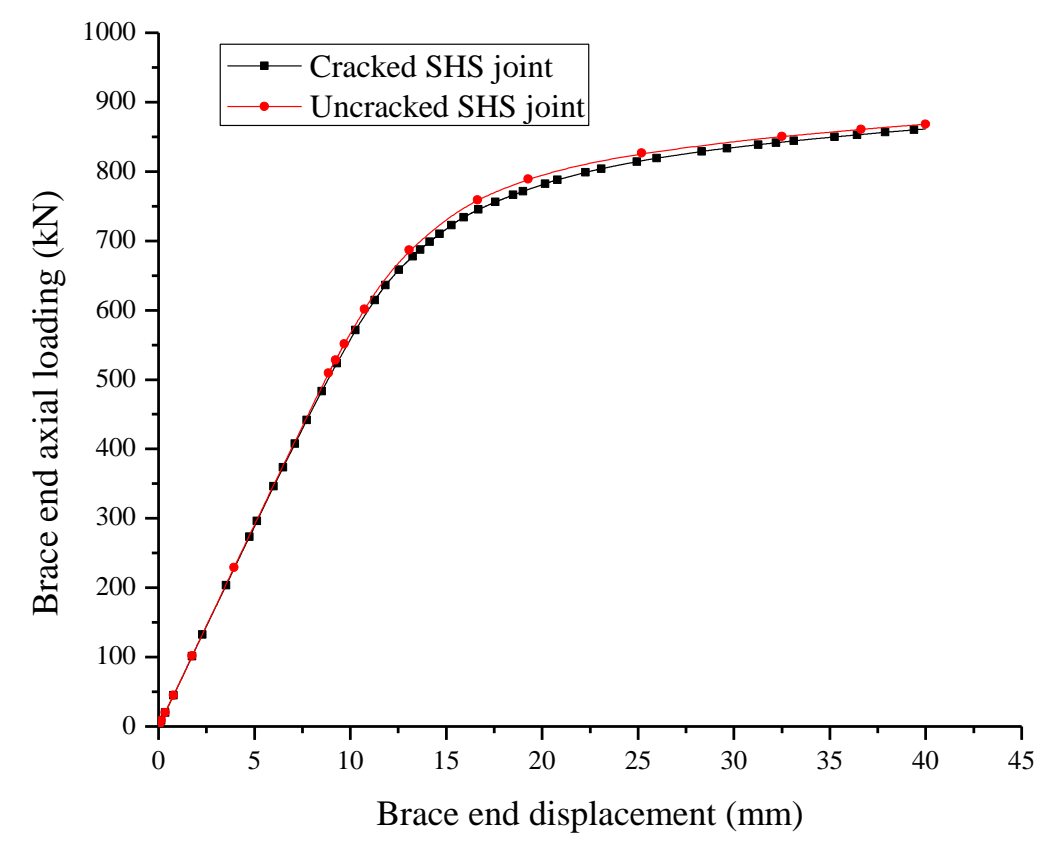

Fig. 14 Sample load vs displacement curve for SHS K-joint

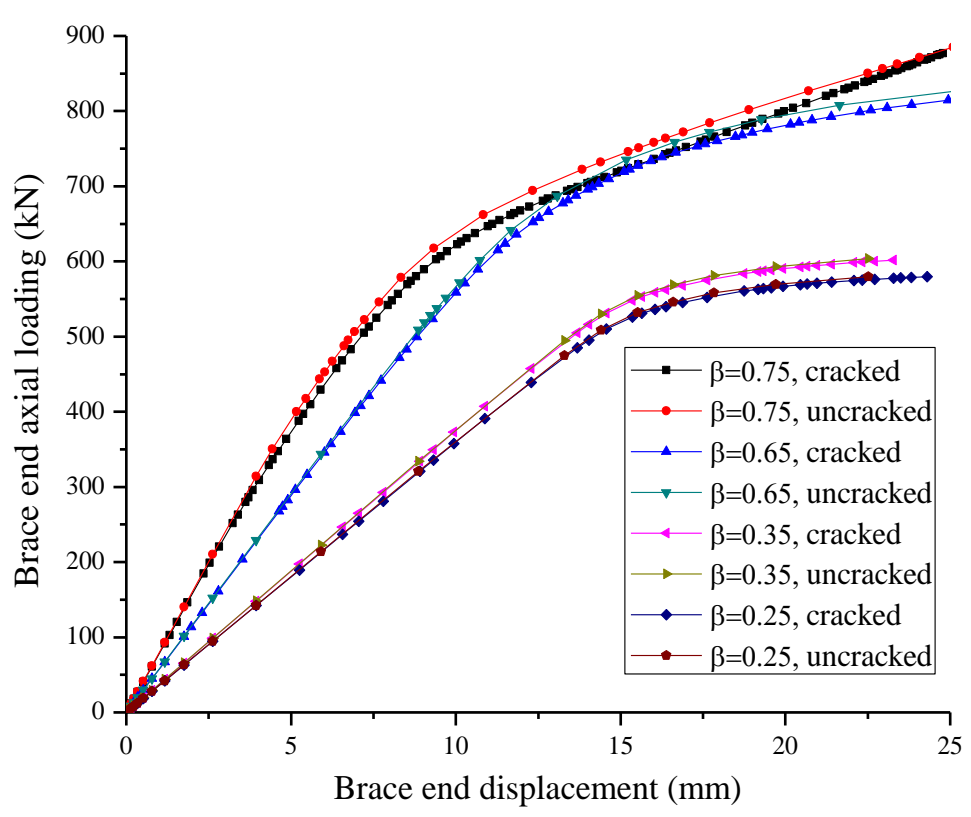

Fig. 15 Load vs displacement curve for crack area factor 5.8\% 


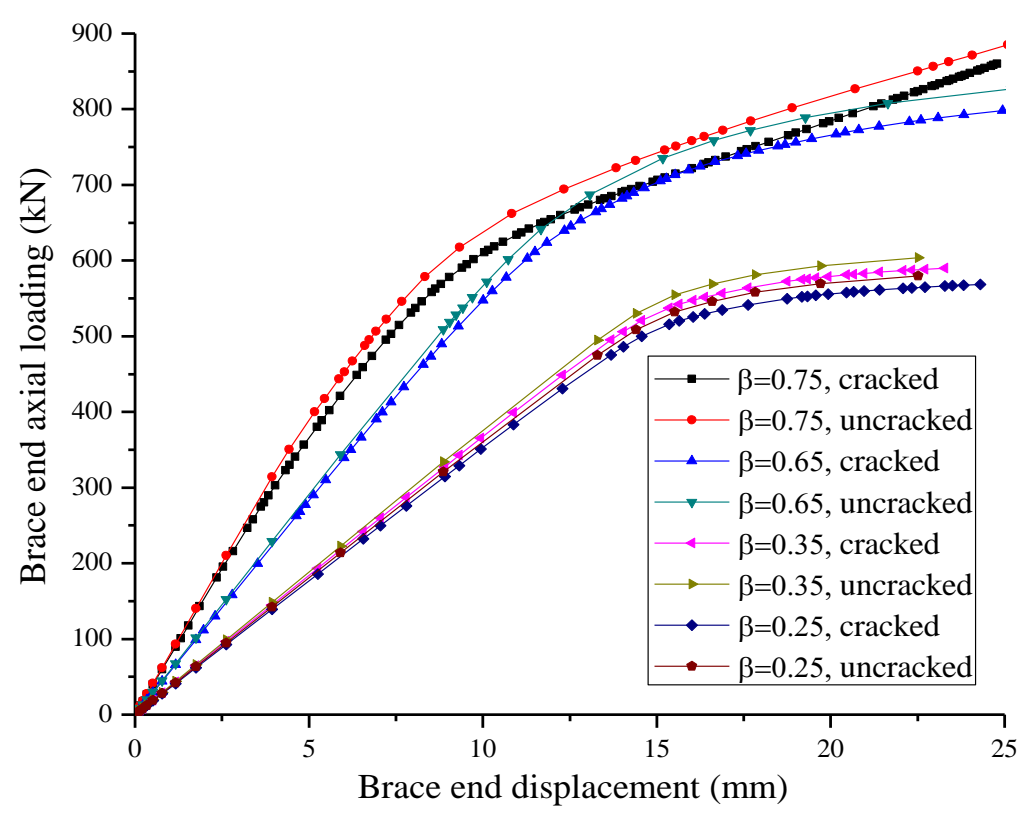

Fig. 16 Load vs displacement curve for crack area factor $10 \%$

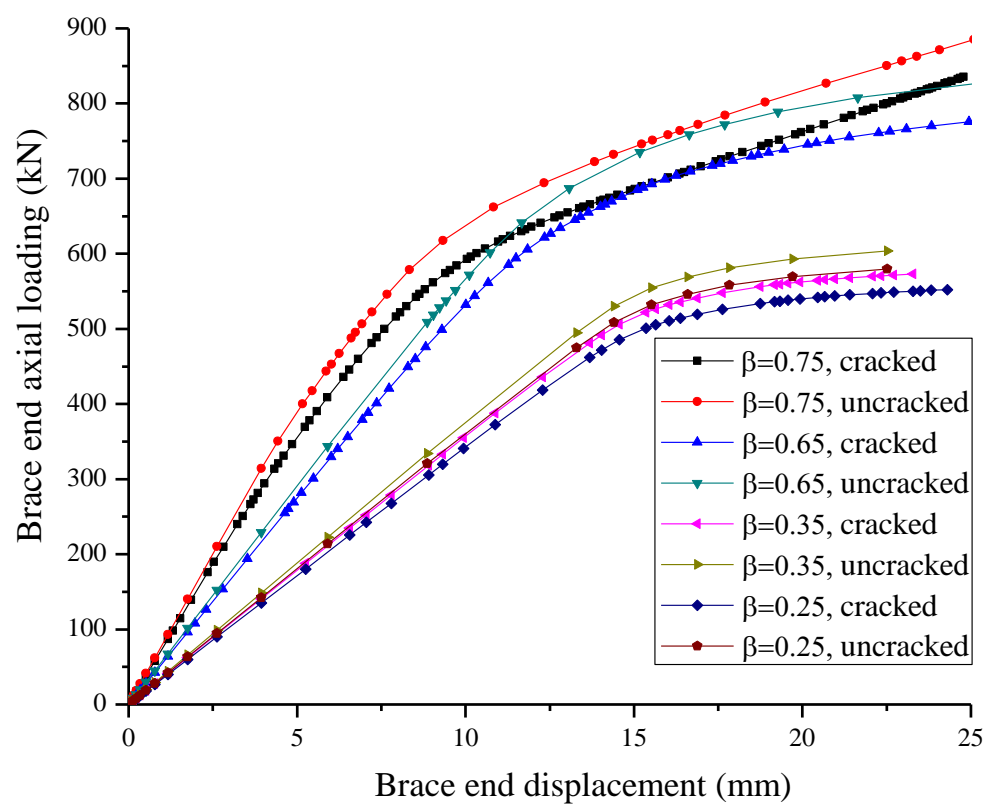

Fig. 17 Load vs displacement curve for crack area factor $20 \%$ 


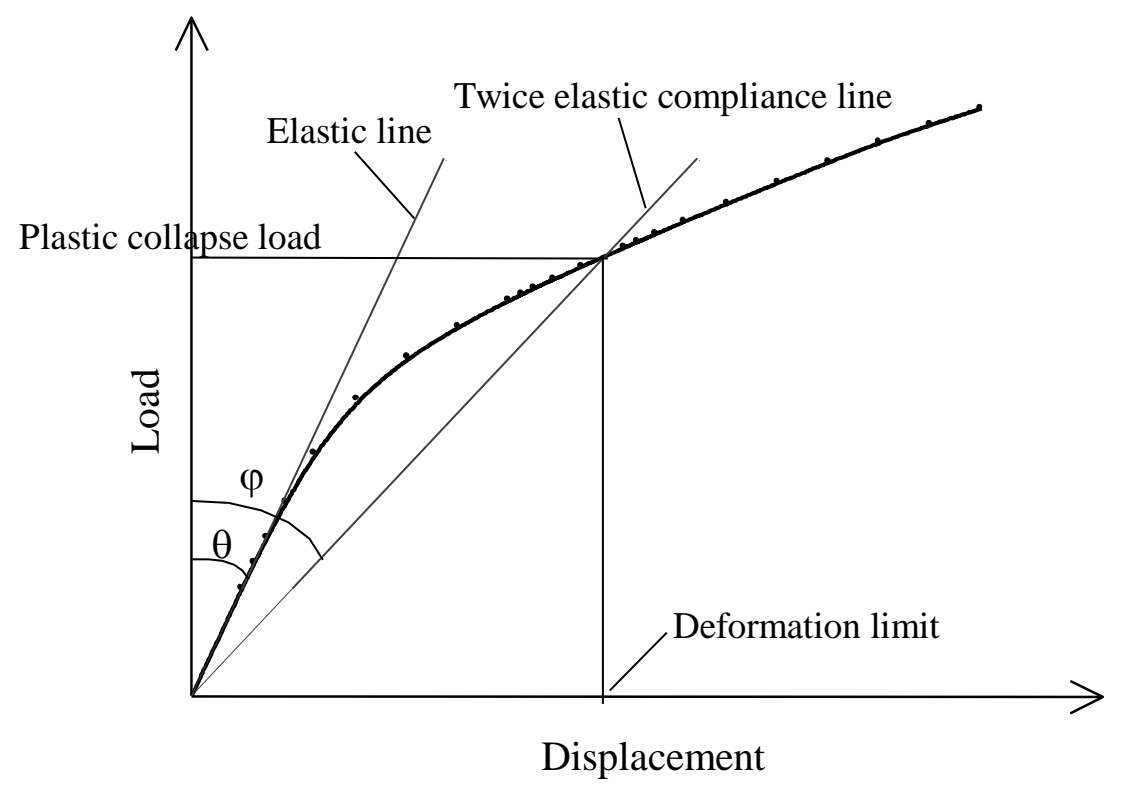

Fig. 18 Twice elastic compliance criterion

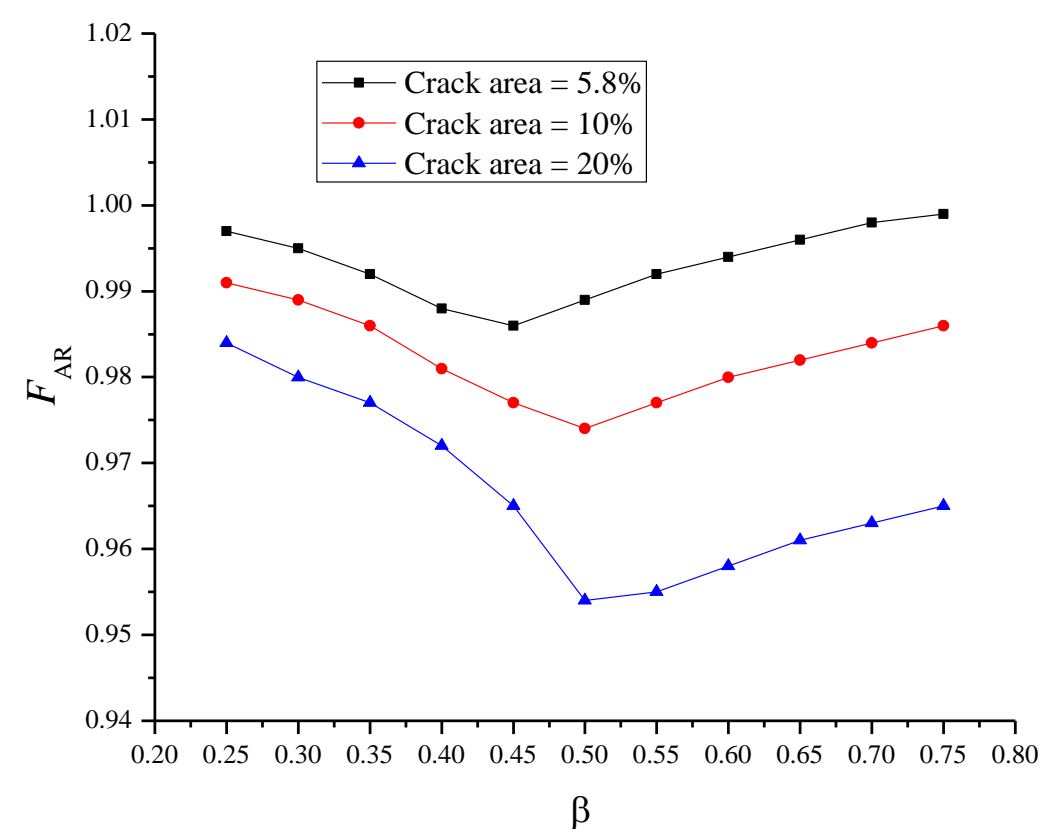

Fig. $19 F_{\text {AR }}$ Vs $\beta$ plot comparison for SHS K-joints 


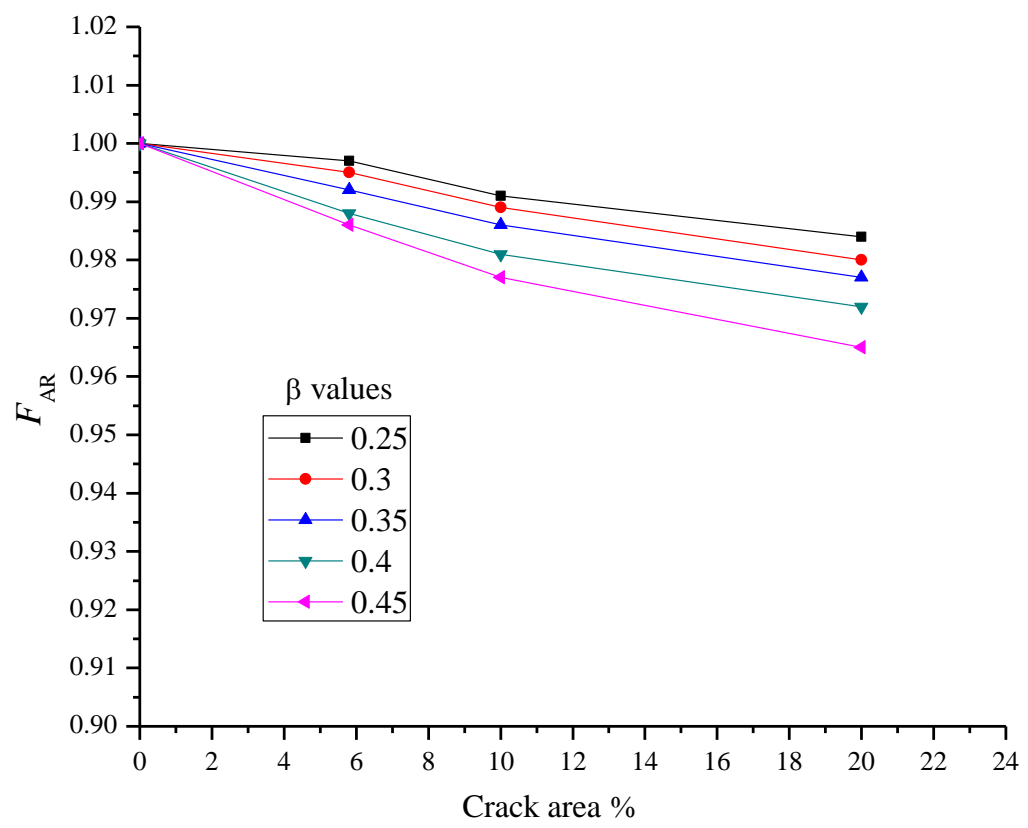

Fig. 20 Comparison of $F_{\mathrm{AR}}$ vs crack area plot for SHS K-joints (for $\beta<0.5$ )

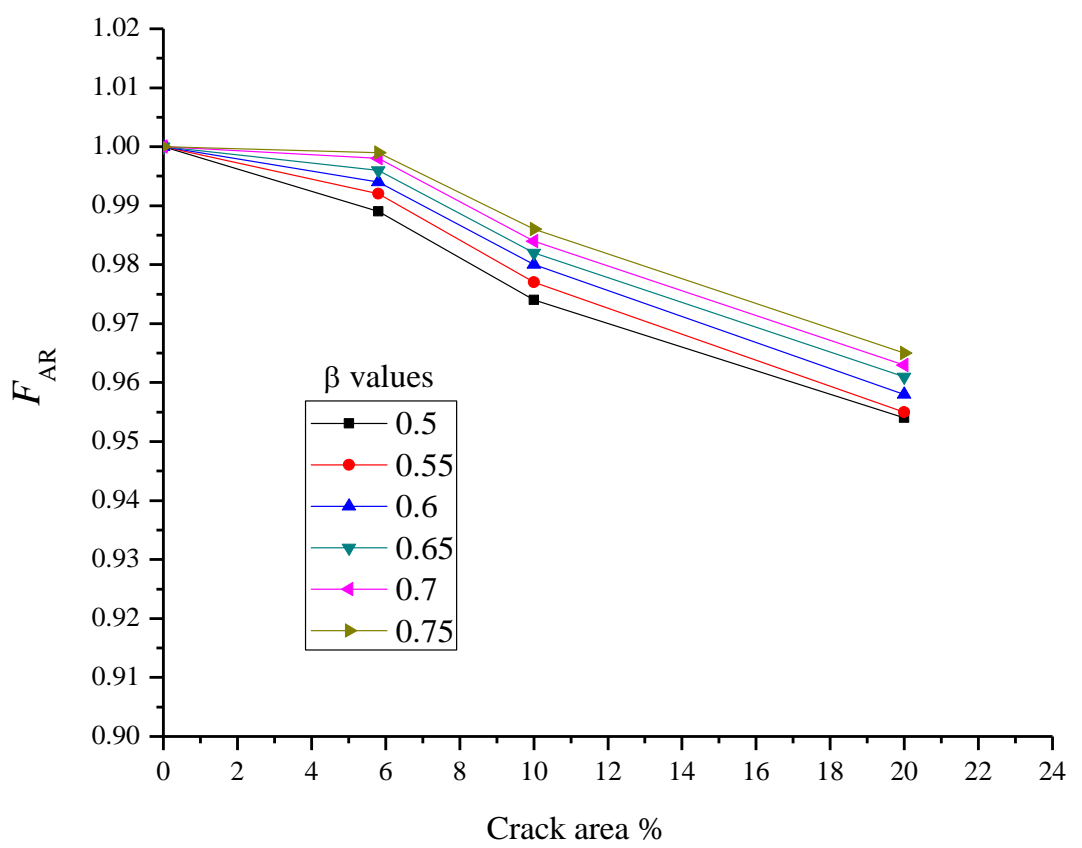

Fig. 21 Comparison of $F_{\mathrm{AR}}$ vs crack area plot for SHS K-joints (for $\beta \geq 0.5$ ) 


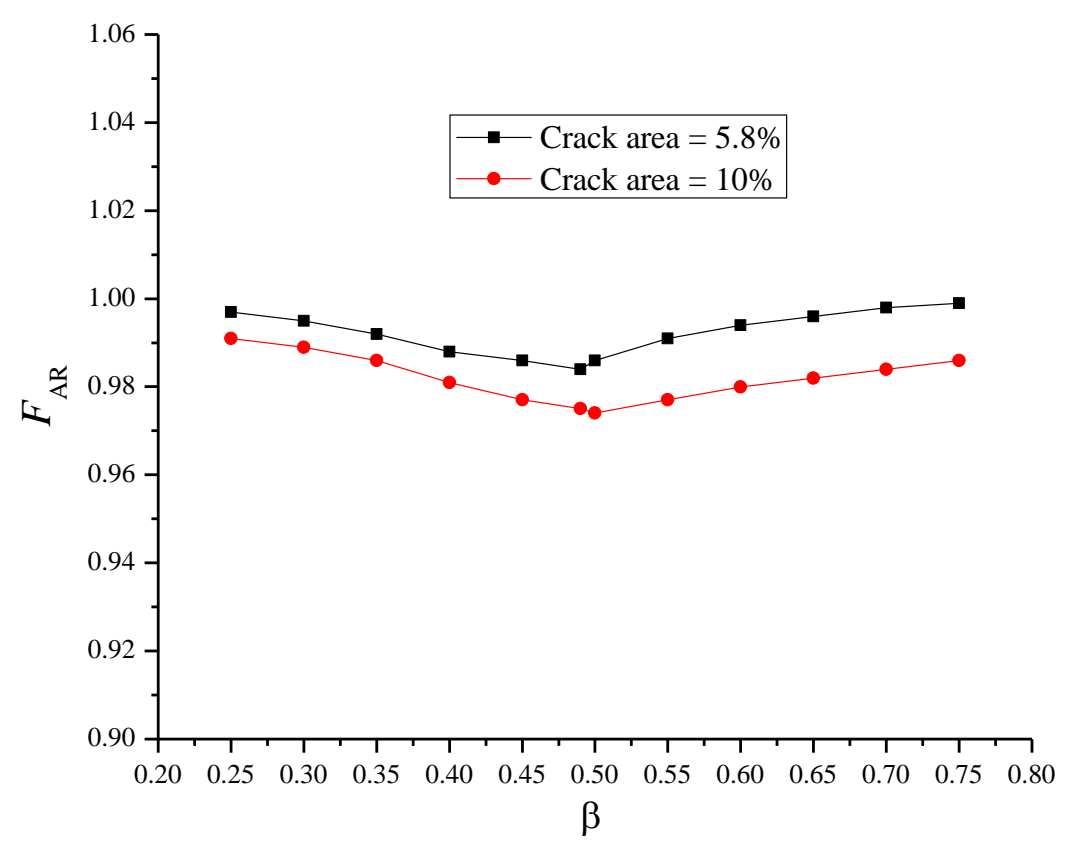

Fig. $22 F_{\mathrm{AR}}$ vs $\beta$ plot comparison for SHS K-joints equation for showing continuity 